\title{
JORNADA DE ACTUALIZACIÓN EN PATOLOGÍA DE LA VÍA AÉREA EN PEDIATRÍA
}

\section{Update on airway pathology in pediatrics}

\author{
Ana Isabel NAVAZO-EGUÍA \\ SACYL. Complejo Asistencial de Burgos. Servicio de Otorrinolaringología. Burgos. España. \\ Correspondencia: navazoeguia@gmail.com
}

Fecha de recepción: 10 de enero de 2018

Fecha de aceptación: 14 de enero de 2018

Fecha de publicación: 15 de enero de 2018

Fecha de publicación del fascículo: 1 de marzo de 2018

Conflicto de intereses: Los autores declaran no tener conflictos de intereses

Imágenes: Los autores declaran haber obtenido las imágenes con el permiso de los pacientes

Política de derechos y autoarchivo: se permite el autoarchivo de la versión post-print (SHERPA/RoMEO)

Licencia CC BY-NC-ND. Licencia Creative Commons Atribución-NoComercial-SinDerivar 4.0 Internacional

Universidad de Salamanca. Su comercialización está sujeta al permiso del editor

\section{Señor director:}

El 7 de octubre de 2016 tuvo lugar en el salón de actos del Hospital Universitario de Burgos la «Primera Jornada de actualización en la patología de la vía aérea en la infancia», organizada por los servicios de Otorrinolaringología y Pediatría y acreditada por la Comisión de Formación Continuada de SACYL.

Esta jornada reunió a más de 50 pediatras, otorrinolaringólogos y cirujanos pediátricos.

Los objetivos principales de la jornada fueron:

- Actualizar los conocimientos sobre algunas de las patologías de vía aérea mas prevalentes en el neonato, lactante y niño.

- Conocer las estrategias diagnósticas a nuestro alcance para la valoración de estos pacientes.
- Exponer pautas de manejo, médico y quirúrgico, ante la patología de vía aérea en pediatría.

El doctor Fernando Gómez Sáez, miembro de la Unidad de Cuidados Intensivos Pediátricos del Hospital Universitario de Burgos, habló de las técnicas de exploración de vía aérea en el paciente pediátrico. Resaltó la importancia de la exploración endoscópica, tanto flexible como rígida de la vía aérea como una técnica sin apenas complicaciones y que puede ofrecer información diagnóstica muy valiosa, así como realizar determinados procedimientos terapéuticos.

La doctora Navazo Eguía, otorrinolaringóloga del Hospital Universitario de Burgos expuso las causas más frecuentes de obstrucción de la vía aérea en la infancia y su manejo.

La doctora Marina González Herrero, cirujana 
pediátrica del Hospital Universitario de Burgos presentó la «Guía de manejo de los cuerpos extraños en la vía aérea infantil».

El doctor Juan L. Antón Pacheco Sánchez, del Servicio de Cirugía Pediátrica del Hospital Doce de Octubre de Madrid, expuso las novedades en el tratamiento quirúrgico y endoscópico de la patología obstructiva de la vía aérea pediátrica y su experiencia en el manejo de endoprótesis y cirugía abierta de las estenosis traqueales.

Por último, el doctor Pedro Pablo Oyagüez de la Unidad de Cuidados Intensivos Pediátricos del Hospital Universitario de Burgos hizo una revisión de su experiencia en la evaluación y soporte respiratorio del paciente con patología de vía aérea.

Las conclusiones más importantes fueron que la patología obstructiva de la vía aérea central, laringe, tráquea y bronquios principales, es afortunadamente poco frecuente en la infancia e incluye un grupo amplio y variado de lesiones congénitas y adquiridas. Representan un problema común entre especialidades médicas y quirúrgicas por lo que el abordaje multidisciplinar en esta patología es imprescindible.

Aunque se ha producido un significativo avance en su manejo, sigue planteando un importante desafío diagnóstico y terapéutico. En muchas ocasiones la decisión del tratamiento de elección no es fácil. La selección de la mejor opción quirúrgica se debe basar en las condiciones locales y generales del paciente. El cirujano debe dominar todas las técnicas y disponibles, para resolver cada situación específica.

La broncoscopia terapéutica, o intervencionista, ha experimentado un gran auge en los últimos años. Clásicamente, la extracción de un cuerpo extraño en la vía aérea o la aspiración de tapones de moco han sido los procedimientos terapéuticos endoscópicos en los niños. Sin embargo, la colocación de endoprótesis traqueales o bronquiales, la dilatación neumática y la cirugía endoscópica asistida por láser son algunas de las técnicas intervencionistas que tienen actualmente indicaciones precisas en la patología de la vía aérea del niño. Aún así, la cirugía reconstructora abierta conserva un papel principal.
Queremos agradecer expresamente al Dr. Juan L. Antón Pacheco su colaboración en esta jornada de formación y en el tratamiento de los casos complicados que le hemos remitido y a Revista ORL por la difusión de esta jornada.

\section{REFERENCIAS}

Acceso a los artículos publicados en Revista $O R L$ de la Jornada de actualización en patología de la vía aérea en pediatría

Gómez-Sáez F, Navazo-Eguía A, Vega-Val C, Gómez-Sánchez E, Mirás-Veiga A, ValenciaRamos J. Exploración de la vía aérea en el paciente pediátrico. Revista ORL [Internet]. 19 May 2017 [citado 14 Ene 2018]. 12p. Disponible http://revistas.usal.es/index.php/2444-

7986/article/view/15900

DOI: http://dx.doi.org/10.14201/orl.15900

González-Herrero M, Ruis-Hierro C, Chamorro-Juárez $R$, Ortega-Escudero $M$, Gutierrez-Dueñas J. Cuerpo extraño en la vía aérea en la edad pediátrica. Revista ORL [Internet]. 7 May 2017 [citado 14 Ene 2018]. 6p. Disponible en: http://revistas.usal.es/index.php/2444-

7986/article/view/15838

DOI: http://dx.doi.org/10.14201/orl.15838

Navazo-Eguía A, Antón-Pacheco-Sánchez J. Obstrucción crónica de la vía aérea en la infancia. Causas más frecuentes. Tratamiento quirúrgico y endoscópico. Revista ORL [Internet]. 14 Jul 2017 [citado 14 Ene 2018]. 17p. Disponible en: http://revistas.usal.es/index.php/2444-

7986/article/view/15901

DOI: http://dx.doi.org/10.14201/orl.15901

Oyagüez-Ugidos P, Blanco-Gómez I, GarcíaGonzález M, Alonso-Álvarez M. Papel de la unidad de cuidados intensivos pediátricos en la evaluación y soporte del paciente con patología de la vía aérea. ¿Cómo lo hacemos? Revista ORL [Internet]. 7 May 2017 [citado 14 Ene 2018]. 7p. Disponible en: http://revistas.usal.es/index.php/2444-

7986/article/view/15902

DOI: http://dx.doi.org/10.14201/orl.15902 